\title{
Guidelines for percutaneous coronary intervention by the Belgian Working Group on Invasive Cardiology
}

\author{
(under the auspices of the Belgian Society of Cardiology) \\ Victor LEGRAND (chair), William WIJNS, Frank VANDENBRANDEN, Edouard BENIT, \\ Jean BOLAND, Marc CLAEYS, Ivan DE SCHEERDER, Thierry EEMANS, Claude HANET, \\ Guy HEYNDRICKX, Pol LAFONTAINE, Pierre MATERNE, Yves TAEYMANS, Christian VRINTS, \\ Mathias VROLIX
}

(Acta Cardiol 2003; 58(4): 34I-348)

Keywords: guidelines - angioplasty - competence.

\section{Introduction}

More than 20.000 percutaneous coronary interventions (PCI) procedures are performed yearly in Belgium. The success of new coronary devices as well as the expanded indications, notably in acute coronary syndromes, suggest a continuous increase in percutaneous revascularization procedures during the following years. Consequently, this increasing need for PCI has encouraged many hospitals to have an interventional programme. In addition, recent trials showing the superiority of PCI for the treatment of AMI, suggest that easy access to primary PCI for all patients would have the greatest potential to salvage the myocardium and reduce mortality. Although urgent surgical back-up is now exceptional thanks to the refinement of PCI materials and adjunctive treatment, performance of PCI still deserves optimal environmental conditions and physician expertise to be carried out with the expected efficacy. Considering the recent developments in interventional cardiology and the Belgian health care system, this document aims to define updated guidelines for the practice of PCI in Belgium.

\section{General considerations}

The BWGIC committee charged to define the guidelines fully endorses the formal recommendations on cardiac catheterization laboratory standards described by the expert committee of the American Heart Association in $2001^{1}$. This document defines the cardiac catheterization laboratory environment, conditions for one day clinic catheterization, quality assessment, procedural and personal issues, ethical concerns, imaging equipment and radiation safety issues.

\section{Evolution of the cardiac catheterization laboratory}

The ongoing technological progress in non-invasive techniques such as fast multiple slice CT or MRI aims at assessing the coronary anatomy in a near future, without selective coronary catheterization ${ }^{2,3}$. This may dramatically reduce the need for diagnostic angiography. On the other hand, further development in X ray and numeric technology, will significantly reduce $\mathrm{X}$ ray exposition and facilitate transmission of angiographic imaging through network systems. Thus, in hospitals without PCI facilities, there is a high likelihood that MRI or CT will replace coronary angiography while hospitals with PCI facilities will have to upgrade to a dedicated imaging network system and new more expensive $\mathrm{X}$ ray equipment especially developed for interventional procedures (flat panel detectors, ultrarapid rotating $\mathrm{C}$-arm, MRI positioning and imaging system...).

\section{Evolution of the medical environment}

Over the past years, our educational and medical system allowed many physicians to become cardiolo-

Address for correspondence: Victor Legrand, Service de Cardiologie,

Fax: + 324 3667837. E-mail: vlegrand@chu.ulg.ac.be

Received March 18, 2003; accepted for publication March 21, 2003. 
gists and the "demand" for cardiologists in Belgium was easily covered by the "offer". On the other hand, our country, like other European countries, has not yet set up specific recommendations for the practice of interventional cardiology. This situation favoured the involvement of many physicians not only in diagnostic but also in therapeutic catheterizations in such a way that the mean number of catheterization per cardiologists involved in this practice is rather low, with only $35 \%$ or 70 physicians performing more than 75 interventions annually (figure 1). Recent decisions regarding access for medical education and specialization will have a dramatic impact on the number of physicians allowed to be trained in cardiology. In addition, the eligibility to practice interventional cardiology will probably be limited to board-certified cardiologists as in the U.S. in order to ensure the quality of operator performance.

\section{Surgical back-up}

Cardiac surgical back-up for PCI has evolved from the formal surgical standby in the 1980's to an informal arrangement of the first available operating room. With the advent of intracoronary stenting, there has been a decrease in the need for emergency coronary artery bypass, ranging between 0.4 and $2 \%$, . Although the need for emergency bypass surgery has decreased very significantly due to the increased experience of the interventional cardiologists and due to the extensive use of coronary stents, serious and possible vital complications still may occur, frequently unexpected and sometimes during the treatment of non-complex and apparently easy to treat lesions. Based on the literature and according to the AHA/ACC guidelines, it appears that although the complication rate of PCI has dramatically decreased, the current standard practice for elective PCI remains the presence of on-site surgical standby ${ }^{1}$. The latter should be organized in such a way that the patient is on artificial circulation

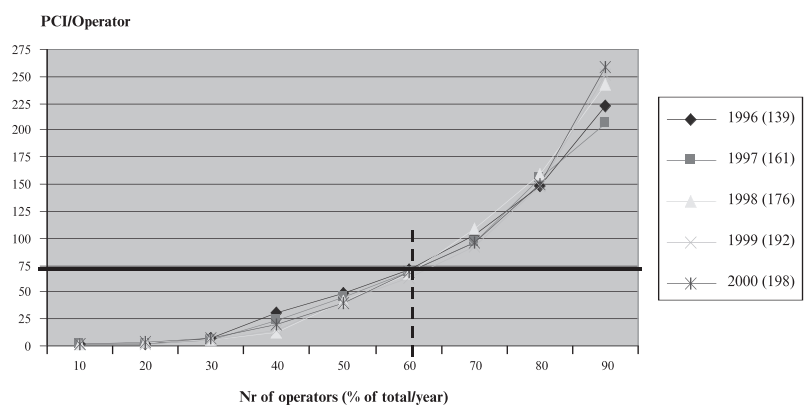

Fig. 1. - Cumulative curves representing the relative number of percutaneous coronary interventions (PCI) performed by individual cardiologists over the last 5 years. Sixty-five percent of interventional cardiologists are doing less than 75 procedures. within 60 minutes after the medical decision to perform urgent bypass surgery. The presence of on-site cardiac surgeons also helps to organize the best therapeutic strategy in complex cases.

\section{Management of acute coronary syndromes (ACS)}

Acute coronary syndromes are a major healthcare problem with still high mortality and morbidity rates. The different clinical presentations of acute coronary syndromes, namely unstable angina and myocardial infarction, share a common underlying pathophysiologic mechanism: atherosclerotic plaque rupture or erosion, with different degrees of superimposed thrombosis and distal embolization. Hence, adequate antiplatelet and antithrombotic therapy remains a cornerstone in the management of both ST elevation MI and non ST-elevation acute coronary syndromes. The specific role of invasive and interventional procedures is highly dependent on the clinical presentation of the ACS and has been discussed in recently published international guidelines ${ }^{6,8}$.

\section{A. Acute coronary syndromes without persistent ST-segment elevation}

Clinical criteria have been developed to stratify the patients into different risk levels. High-risk patients include those with recurrent ischaemia, early postinfarction angina, elevated troponin levels, haemodynamic instability and major arrhythmias. In those patients coronary angiography should be planned as soon as possible (within $48 \mathrm{~h}$ ), but without undue urgency. Meanwhile treatment with heparin and GPIIb/

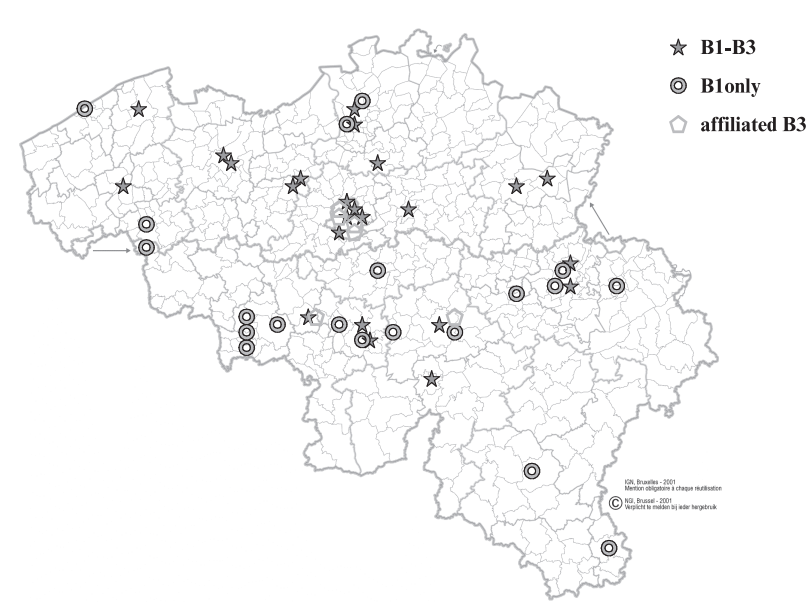

Fig. 2. - Geographical distribution of invasive cardiac centres. Complete cardiac B programmes (stars) involve 24 centres (including sites in 6 affiliated hospitals). Diagnostic B1 centres (circle) are present in 20 hospitals, mostly located in Wallonia $(16 / 20)$. 
IIIa should be started. Based on angiographic findings coronary intervention can be carried out. Such an invasive approach has been shown to reduce death and reinfarction rate by $25 \%$, as compared to a conservative approach. In addition, symptoms of angina and the need for re-admissions were almost halved by an invasive approach. Patients not fulfilling the high-risk criteria can be managed conservatively with appropriate anti-thrombotic, anti-platelet and anti-anginal drugs. The decision for invasive evaluation is mainly based on the documentation of residual ischaemia on a stress test or by a history of coronary revascularization. In this setting coronary angiography and coronary intervention can be carried out electively.

B. Acute coronary syndromes with persistent ST-segment elevation or new onset left bundle-branch block

The major goal in the treatment of AMI is the rapid restoration of the epicardial blood flow and myocardial perfusion in the infarct zone. In principle, two validated reperfusion strategies might be considered: the pharmacological approach with fibrinolysis or the mechanical approach with immediate coronary angiography and PCI of the occluded infarct artery. Immediate PCI without thrombolytic therapy (also known as "primary" PCI) has been shown to offer a substantial benefit over fibrinolysis in terms of patency rate ( $85 \%$ versus $60 \%$ restoration of TIMI 3 flow) and in terms of event-free survival. A meta-analysis of these trials showed a reduction in 30-day mortality from $6.5 \%$ to $4.4 \%$ and a reduction in stroke from $2 \%$ to $0.7 \%$, compared with fibrinolytic therapy ${ }^{9,10}$

It should be acknowledged, however, that these results reflect performance by highly experienced operators working in centres committed to primary PCI. In addition, the outcome of primary PCI has been shown to be also highly dependent on the time delay between hospital arrival and PCI. If the door-to-balloon time exceeds 90 minutes, in-hospital mortality increases substantially so that the benefit of primary PCI over fibrinolysis vanishes ${ }^{11}$. Accordingly, when patients present directly to a qualified primary PCI centre, prompt primary angioplasty constitutes the optimal therapy for STEMI provided that the door-to-balloon time is less than 90 minutes. In some community hospitals with diagnostic cardiac catheterization facilities (but no elective PCI programme), skilled operators who perform elective PCI in nearby tertiary facilities could also perform primary PCI. Such hospitals have demonstrated results that are comparable to those obtained by primary PCI centres ${ }^{12,13}$.

The situation for patients presenting to hospitals without cathlab facilities, is more complex and still under investigation. Rapid transfer to a hospital with
PCI facilities might be an option. This approach has recently been validated in the DANAMI $2^{14}$ and PRAGUE 2 trials $^{15}$. It should be pointed out that a well-organized transport system between community and referral centers allowing a door-to-balloon time less than 90 minutes is a prerequisite for obtaining such favourable results.

Treatment with optimal pharmacological reperfusion therapy and referring patients for PCI only in case of evidence of failed reperfusion might be another option, especially in haemodynamically stable patients with small or moderately sized infarctions. Recent data suggest that the efficiency gap between thrombolysis and primary PCI could be reduced with this approach, provided that PCI is performed within 150 minutes after the initiation of thrombolysis. This implies that the decision for urgent angiography and option for rescue PCI should be taken 60-90 minutes following initiation of thrombolytic therapy.

Moreover, one might consider the concept of facilitated PCI where patients are pretreated with thrombolytic agents and/or IIB/IIIA receptor blockers (in-hospital or pre-hospital) and then referred for angiography with the option of $\mathrm{PCI}^{16,19}$. There is already some clinical evidence that such an approach results in a greater incidence of infarct artery patency on initial angiography and that it might yield outcome results comparable with primary $\mathrm{PCI}^{17}$. The exact role of this approach is now being evaluated intensively in several adequately powered trials. In the meantime, the decision between local thrombolytic therapy, local primary PCI, and transfer to a primary angioplasty centre should be made individually and depends on several factors, including anticipated time of transfer, patient condition, local community infrastructure, medical transport system ${ }^{20,21}$.

Finally, cardiogenic shock less than 36 hours post MI in patients less than 75 years old is considered as a clear emergency indication for acute revascularization in adequately experienced laboratories; the absolute benefit in survival is of 20 and $18 \%$ at 6 and 12 months, respectively ${ }^{22,23}$.

\section{Organization of transfer for primary angioplasty}

Mechanical reperfusion of MI by PCI ideally includes fast and direct transfer to a catheterization laboratory. There is still ongoing debate on whether "quick and dirty" transport organized by paramedics with a conventional ambulance equipped with a defibrillator is preferable to a "slow and clear" system which requires transportation by intensive care vehicle with physician and nurses on board, usually belonging to the specialized hospital. The recent PRAGUE and DANAMI trials as well as the Zwolle experience demonstrated the low risk of complications using a 
"quick and dirty" transfer system and support superiority of PCI over thrombolysis in patients transported to a specialized center within 90 minutes ${ }^{14,15,26}$. On the other hand, absence of medical support during inter hospital transportation may raise some legal and ethical issues in case of complications. In our view, this should not be an argument to delay or postpone quick transportation of a patient without cardiogenic shock by conventional transfer ambulance system. Under these circumstances, the specialized centre should endorse the responsibility of the transportation. When readily available or in case of transportation of a patient in cardiogenic shock, mobile intensive care ambulance with physician and nurse on board are recommended.

\section{Belgian Cardiac Programme}

The law defines cardiac catheterization settings. It includes centres with a cardiovascular surgical program (complete B programme) $(\mathrm{n}=24)$ but also community hospitals without cardio-surgical programme $(n=20)$, only allowed to do diagnostic catheterizations (B1 centres). Most centres are concentrated in the urban areas,

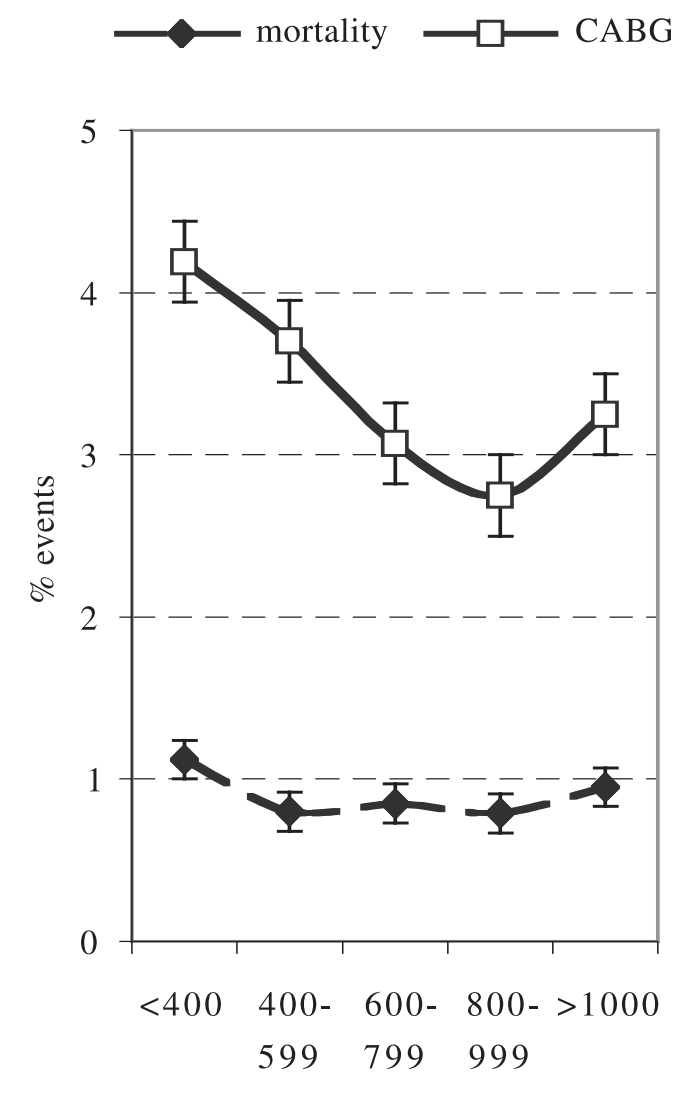

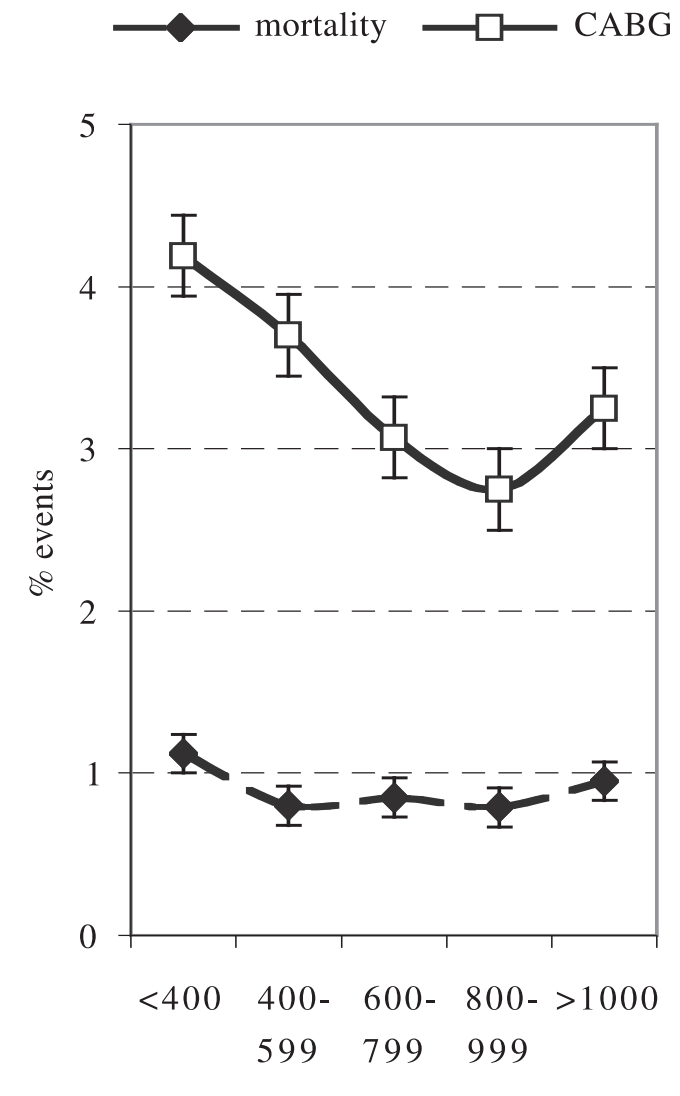

Hospital volume/year with more diagnostic (B1) centres in Wallonia as compared to Flanders (figure 2). Community hospitals without cardiac surgery capability are not allowed to perform therapeutic invasive procedures (this situation is referred to as $\mathrm{B} 2$ centre).

The availability for therapeutic procedures in actual B1 centres could reduce the need for unnecessary repeat catheterization, allow faster revascularization of AMI by PCI, or avoid transportation issues, all potential sources of cost savings for the health care system. In evaluating the potentials of this additional value, it is important to consider that most smaller B1 hospitals cannot meet the procedure volume requirements, neither the personal (nurses, technicians, physicians) availability nor the equipment standards to do interventions on a 24/24 hour basis. We must also recognize that the current situation allows immediate access for revascularization strategies on routine basis without a waiting list for surgical or percutaneous interventions.

In the final analysis, the regulatory authorities should consider clinical effectiveness and quality improvement, rather than unproven cost savings. Only compliance to the recommendations and guidelines described below can guarantee quality improvement.

Fig. 3. - Relation between procedural outcome and hospital caseload (left) and operator caseload (right) in the 1994 New York State registry. Redrawn from Hannan et al. ${ }^{30}$. 


\section{Recommendations}

\section{A. Elective PCI}

\section{a. Optimal operator and hospital volume: current evidence}

There are consistent data showing a significant correlation between short-term complications of percutaneous intervention (emergency $\mathrm{CABG}$ and mortality) and the activity level of both cardiovascular centres and individual operators ${ }^{25,31}$. Based on PCI registries during the first half of the nineties many reports have demonstrated that hospitals in which fewer PCI's are performed have a greater incidence of procedurerelated complications, notably death and need for bypass surgery for failed intervention, than hospitals performing more procedures (table 1). The relationship between complication levels and activity levels is curvilinear with rates decreasing as the activity of the hospital increases to 600 procedures/year and operator activity increases to 175 procedures/year (figure 3 ). Operators with an activity $<75$ procedures/year have a significant higher death and emergency $\mathrm{CABG}$ rate than operators with an annual volume of $>75$ procedures.

The relation between operator experience and clinical outcome in the stent era was analysed by Kastrati et al. ${ }^{32}$. They found that in addition to patient and lesion characteristics, operator experience was a significant predictor of clinical outcome after stent placement: operator volumes above 483 procedures were associated with an adverse outcome rate of $1.70 \pm 1.28 \%$ whereas operators with an annual volume less than 90 procedures were associated with an adverse outcome rate of $4.59 \pm 1.17 \%$. These data were also confirmed by a recent Medicare registry ${ }^{33}$ and recent presentations $^{34}$. (figure 4).

\section{b. Guidelines for elective PCI}

The education in interventional cardiology has been described previously ${ }^{35}$. Based on the findings of several PCI registries published in the literature and on the guidelines on optimal annual operator and hospital volume that were proposed in order to guarantee sufficient quality and safety for invasive and interventional heart catheterization procedures, the following recommendations can be made ${ }^{1,36}$ (table 2):

1. an interventional cardiologist should perform at least 250 diagnostic catheterizations per year;

2. an interventional cardiologist should perform at least $\geq 75$ interventional procedures per year in order to maintain his manual experience and optimally $\geq 150$ interventional procedures per year in order to adapt his practice rapidly to the evolving progress in the field;

3 . a cardiac centre with an annual volume $>600$ interventional procedures per year is considered optimal for providing the highest standards of patient care;

4. a cardiac centrewith an annual volume between 400 and 600 intervention procedures per year is sufficient for guaranteeing a satisfactory quality of patient care;

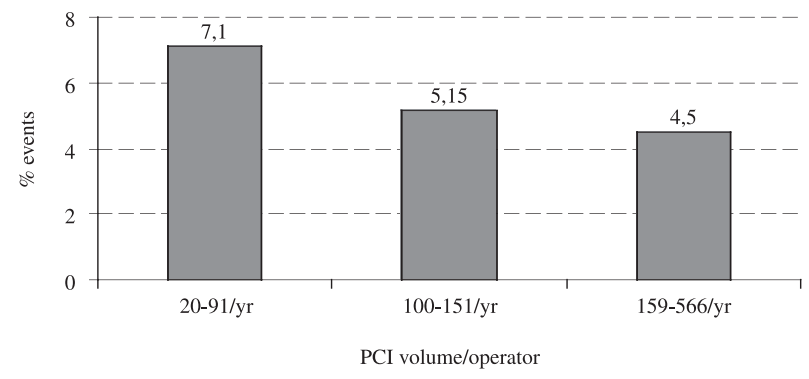

Fig. 4. - Relationship between operator annual volume and clinical outcome in the stent era (data from PCI registry of 25144 PCI 1997-2001; with stenting rate from $73.8 \% \geq 86.6 \%)^{34}$.

Table 1a. - relation between hospital volume vs. outcome

\begin{tabular}{lcccccc}
\hline Study & period & sample & Pts/hospitals & death & CABG & threshold \\
\hline Ritchie $^{25}$ & 1989 & California & $24,883 / 110$ & yes & yes & $>200 / \mathrm{y}$ \\
Jollis $^{26}$ & $1987-90$ & Medicare & $217,836 / 1,194$ & no & yes & $>200 / \mathrm{y}$ \\
Kimmel $^{27}$ & $1992-93$ & SCA \& I & $19,594 / 48$ & no & yes & $>400 / \mathrm{y}$ \\
Jollis $^{28}$ & 1992 & Medicare & $97,498 / 984$ & yes & yes & $\geq 200 / \mathrm{y}$ \\
Hannan $^{30}$ & $1991-94$ & NY state & $62,670 / 984$ & yes & yes & $>600 / \mathrm{y}$ \\
\hline
\end{tabular}

Table 1b. - operator volume vs. outcome

\begin{tabular}{lcccccc}
\hline Study & period & sample & Pts/operators & death & CABG & threshold \\
\hline McGrath $^{29}$ & $1990-93$ & N. NE & $12,033 / 31$ & no & yes & $>85 / \mathrm{y}$ \\
Hannan $^{30}$ & $1991-94$ & NY state & $62,670 / ?$ & yes & yes & $>100 / \mathrm{y}$ \\
Jollis $^{28}$ & 1992 & Medicare & $97,498 / 97$ & no & yes & $>50 / \mathrm{y}$ \\
Ellis $^{31}$ & 1993 & & $12,941 / 38$ & yes & yes & $>100 / \mathrm{y}$ \\
\hline
\end{tabular}


5. continuation of activity in a centre with a case load comprised between 250 and 400 procedures can be permitted under some conditions:

a. the operators have an individual annual volume of at least 75 interventional procedures per year

b. this centre should be affiliated with a high-volume centre in an integrated network (share a common agreement) and work with a close cooperation in order to have:

i. common diagnostic and therapeutic procedural guidelines,

ii. common quality assessment,

iii. formal organization of referrals of difficult and complex cases,

iv. participation of very experienced operators from the co-operating high volume center

v. rotation of operators between low and highvolume centres,

6. continuation of interventional activity of a cardiac centre performing less than 250 interventional procedures per year after three years of functioning should be questioned.

\section{B. PRimary PCI}

\section{a. Optimal operator and hospital volume: current evidence}

Several studies have shown that also in primary PCI there is a strong association between institutional and individual procedural volumes and clinical outcome, including mortality ${ }^{11,37-39}$.

It appears thus preferable that primary PCI should be used as an alternative to thrombolytic therapy only if performed in a timely fashion by individuals skilled in the procedure and supported by experienced personnel in high-volume centres.

\section{b. Guidelines for primary PCI}

Based on these studies the following recommendations can be made concerning the performance of primary PCI for acute myocardial infarction in centres which fulfill the minimal criteria for elective PCI as mentioned above (table 2):
1. The operators must be experienced interventional cardiologists who regularly perform elective interventions (at least $>75$ cases/year and optimally $>150$ cases/year). The institution should meet the volume criteria for elective PCI and treat a minimum of 36 patients by primary PCI for acute myocardial infarction per year and optimally $\geq 57$ per year. In addition, each operator must perform a minimum of 12 primary PCI for acute myocardial infarction per year.

2. A cardiac centre should involve at least 2 experienced interventional cardiologists.

3. The nursing and technical catheterization laboratory staff must be experienced in handling acutely ill patients and be comfortable with interventional equipment. They must participate in a 24-h, 365-day call schedule.

4. The catheterization laboratory must be well equipped, with optimal imaging systems, resuscitation equipment, IABP support and a broad array of interventional equipment.

5. The cardiac care unit nurses must be adept in haemodynamic monitoring and IABP management.

6. There must be formalized written protocols in place for immediate (within 1 hour) and efficient transfer of patients for emergency CABG, and these protocols should be reviewed and tested on a regular (quarterly) basis.

7. Primary intervention must be performed routinely as the treatment of choice around the clock for a large proportion of patients with acute myocardial infarction to ensure streamlined care paths and increased case volumes.

8. Case selection for the performance of primary angioplasty must be rigorous. There must be an ongoing programme of outcome analysis and formalized periodic case review.

9. Institutions should have a formalized primary PCI programme instituted that includes establishing standards, training staff, developing detailed logistics and creating a quality assessment and error management system.

\section{Quality assessment}

In order to examine the quality of care, it is necessary to register patients and procedure-related data in

Table 2. - Minimal and optimal hospital and operator volume

\begin{tabular}{lcccc}
\hline & Hospital & Optimal & Operator & Minimal \\
& Minimal & Optimal \\
\hline Elective PCI & $400 \mathrm{PCI} /$ year & $\geq 600 \mathrm{PCI} /$ year & $>75 \mathrm{PCI} /$ year & $\geq 125 \mathrm{PCI} /$ year \\
Primary PCI* & $\geq 36 \mathrm{PCI} /$ year & $\geq 57 \mathrm{PCI} /$ year & $>12 \mathrm{PCI} /$ year & \\
\hline
\end{tabular}

* In hospitals with minimum caseload volume (400 PCI/year) and by operators with minimum caseload experience (> 75 PCI/year). 
all catheterization procedures. These data should be used as quality indicators to assess the compliance to clinical practice guidelines, resources, clinical results and outcomes. These quality indicators should be recognized as meaningful for the medical profession, the authorities and patient care. A minimal data set of information should be systematically provided in order to have dynamic data on the health care process. Furthermore, audits may be performed analysing particular situations at a certain point in time by appropriate questionnaires. Recording of quality indicators should be part of the procedure and linked to its reimbursement.

\section{Conclusions}

The field of coronary intervention has expanded dramatically over the past decade and will continue to evolve over the next several years. In order to keep a standard of quality and to provide the best treatment for patients undergoing coronary interventions, it is of paramount importance to allow practice of PCI based on demonstration of safety and efficacy. The present document proposes guidelines and recommendations inspired on the current knowledge and derived from randomized clinical studies and/or large registries. Rigorous application of these criteria is critical to assure safe and effective therapy and provide overall clinical utility to patients with coronary artery disease. Physician practice as well as centre agreement should be based only on sound evidence-based data provided in this document.

\section{References}

1. Smith SC, Jr, Blair SN, Bonow RO, Brass LM, Cerqueira MD, Dracup K, Fuster V, Gotto A, Grundy SM, Miller NH, Jacobs A, Jones D, Krauss RM, Mosca L, Ockene I, Pasternak RC, Pearson T, Pfeffer MA, Starke RD, Taubert KA. ACC/AHA guidelines for percutaneous coronary intervention (revision of the 1993 PTCA guidelines)-executive summary: a report of the American College of Cardiology/American Heart Association task force on practice guidelines (Committee to revise the 1993 guidelines for percutaneous transluminal coronary angioplasty) endorsed by the Society for Cardiac Angiography and Interventions. Circulation 2001; 103: 301941.

2. Fayad ZA, Fuster V, Nikolaou K, Becker C. Computed Tomography and Magnetic Resonance Imaging for Noninvasive Coronary Angiography and Plaque Imaging: Current and Potential Future Concepts. Circulation 2002; 106: 20262034.

3. Ropers D, Baum U, Pohle K, Anders K, Ulzheimer S, Ohnesorge B, Schlundt C, Bautz W, Daniel WG, Achanbach S. Detection of Coronary Artery Stenoses With Thin-Slice Multi-Detector Row Spiral Computed Tomography and Multiplanar Reconstruction. Circulation 2003; 107: 664-666.
4. Shubrooks SJ Jr, Nesto RW, Leeman D, Waxman S, LEwis SM, Fitzpatrick P, Dib N. Urgent coronary bypass surgery for failed percutaneous coronary intervention in the stent era: Is backup still necessary? Am Heart J 2001; 142: 190-6.

5. Seshadri N, Whitlow P, Acharya N, Houghtaling P, Blackstone EH, Ellis SG. Emergency Coronary Artery Bypass Surgery in the Contemporary Percutaneous Coronary Intervention Era. Circulation 2002; 106: 2346-2350.

6. Braunwald E, Antman EM, Beasley JW, Califf RM, Cheitlin MD, Hochman JS, Jones RH, Kerejiakes D, Kupersmith J, Leven TN, Pepine CJ, Schaeffer JW, Smith EE $3^{\text {rd }}$, Steward DE, Thereoux P, Gibbons RJ, Alpert JS, Faxon DP, Fuster V, Gregoratos G, Hiratzka LF, Jacobs AK, Smith SR Jr. ACC/AHA 2002 guideline update for the management of patients with unstable angina and non-ST-segment elevation myocardial infarction - summary article: a report of the American College of Cardiology/American Heart Association task force on practice guidelines (Committee on the Management of Patients With Unstable Angina). J Am Coll Cardiol 2002; 40: 1366-74.

7. Bertrand ME, Simoons ML, Fox KA, Wallentin LC, Hamm CW, McFadden E, De Feyter PJ, Specchia G, Ruzyllo W. Management of acute coronary syndromes in patients presenting without persistent ST-segment elevation. Eur Heart $J$ 2002; 23: 1809-40.

8. Van de Werf F, Ardissino D, Betriu A, Collinos DV, Falk E, Fox KA, Julian D, Lengyel M, Neumann FJ, Ruzyllo W, Thygesen C, Underwood SR, Vahanian A, Verheugt FW, Wijns W. Management of acute myocardial infarction in patients presenting with ST-segment elevation. Eur Heart $J$ 2003; 24: 28-66.

9. Keeley EC, Boura JA, Grines CL. Primary angioplasty versus intravenous thrombolytic therapy for acute myocardial infarction: a quantitative review of 23 randomised trials. Lancet 2003: 361: 13-20.

10. Grines C, Patel A, Zijlstra F, Weaver WD, Granger C, Simes RJ. Primary coronary angioplasty compared with intravenous thrombolytic therapy for acute myocardial infarction: six-month follow up and analysis of individual patient data from randomized trials. Am Heart J 2003; 145: 47-57.

11. Cannon CP, Gibson CM, Lambrew CT, Shoultz DA, Levy D. Relationship of symptom-onset-to-balloon time and door-to-balloon time with mortality in patients undergoing angioplasty for acute myocardial infarction. Jama 2000; 283: 2941-7.

12. Wharton TP Jr, McNamara NS, Fedele FA, Jacobs MI, Gladstone AR, Funk EJ. Primary angioplasty for the treatment of acute myocardial infarction: experience at two community hospitals without cardiac surgery. $J$ Am Coll Cardiol 1999; 33: 1257-65.

13. Aversano T, Aversano LT, Passamani E, Knatterud GL, Terrin ML, Williams DO, Forman SA. Thrombolytic therapy vs primary percutaneous coronary intervention for myocardial infarction in patients presenting to hospitals without on-site cardiac surgery: a randomized controlled trial. Jama 2002; 287: 1943-51.

14. Andersen H, DANAMI-2: The Danish multicenter randomized study on thrombolytic therapy versus acute coronary angioplasty in acute myocardial infarction. Late breaking clinical trials. American College of Cardiology, March 2002. http://www.danami-2.dk, 2002.

15. Widimsky P, Budesinsky T, Vorac D, Groch L, Zelizko M, Aschermann M, Branny M, St'asek J, Formanek P. Long distance transport for primary angioplasty vs immediate 
thrombolysis in acute myocardial infarction. Final results of the randomized national multicentre trial-PRAGUE-2. Eur Heart J 2003; 24: 94-104.

16. Cannon CP. Bridging the gap with new strategies in acute ST elevation myocardial infarction: bolus thrombolysis, glycoprotein IIb/IIIa inhibitors, combination therapy, percutaneous coronary intervention, and "facilitated" PCI. J Thromb Thrombolysis 2000; 9: 235-41.

17. Herrmann HC, Moliterno DJ, Ohman EM, Stebbins AL, Bode C, Betriu A, Forycki F, Miklin JS, Bachinsky WB, Lincoff AM, Califf RM, Topol EJ. Facilitation of early percutaneous coronary intervention after reteplase with or without abciximab in acute myocardial infarction: results from the SPEED (GUSTO-4 Pilot) Trial. J Am Coll Cardiol 2000; 36: 1489-96.

18. Cantor WJ and Ohman EM. "Facilitated" PCI for Acute MI: PCI with Lysis and Platelet Inhibition. Curr Interv Cardiol Rep 2001; 3: 321-329.

19. Herrmann HC, Kelley MP, Ellis SG. Facilitated PCI: rationale and design of the FINESSE trial. $J$ Invasive Cardiol 2001; 13(Suppl A): 10A-15A.

20. Ribichini F, Wijns W. Acute myocardial infarction: reperfusion treatment. Heart 2002; 88: 298-305.

21. Dalby M, Montalescot G. Transfer for primary angioplasty: who and how? Heart 2002; 88: 570-2.

22. Hochman JS, Sleeper LA, Webb JG, Sanborn TA, White MD, Talley JD, Buller CE, Jacobs AK, Slater JN, Col J, McKinlay SM, LeJemtel TH. Early revascularization in acute myocardial infarction complicated by cardiogenic shock. SHOCK Investigators. Should We Emergently Revascularize Occluded Coronaries for Cardiogenic Shock. $N$ Engl $J$ Med 1999; 341: 625-34.

23. Hochman JS, Sleeper LA, White HD, Dzavik V, Wong SC, Menon V, Webb JG, Steingart R, Picard MH, Menegus MA, Boland J, Sanborn T, Buller CE, Modur S, Forman R, Desvigne-Nickens P, Jacobs AK, Slater JN, LeJemtel TH. One-year survival following early revascularization for cardiogenic shock. Jama 2001; 285: 190-2.

24. Zijlstra F, Ernst N de Boer MJ, Nibbering E, Suryaprarnata H, Hoorntje JC, Dambrink JH, van't Hof AW, Verheugt FW. Influence of prehospital administration of aspirin and heparin on initial patency of the infarct-related artery in patients with acute ST elevation myocardial infarction. $\mathrm{J} \mathrm{Am}$ Coll Cardiol 2002; 39: 1733-7.

25. Ritchie JL, Maynard C, Chapko MK, Every NR, Martin DC. Association between percutaneous transluminal coronary angioplasty volumes and outcomes in the Healthcare Cost and Utilization Project 1993-1994. Am J Cardiol 1999; 83: 493-7.

26. Jollis JG, Peterson ED, DeLong ER, Mark DB, Collins SR, Muhlbaier LH. The relation between the volume of coronary angioplasty procedures at hospitals treating Medicare beneficiaries and short-term mortality. $N$ Engl J Med 1994; 331: 1625-9.

27. Kimmel SE, JA Berlin, Laskey WK. The relationship between coronary angioplasty procedure volume and major complications. Jama 1995; 274: 1137-42.

28. Jollis JG, Peterson ED, Nelson CL, Stafford JA, DeLong ER, Muhlbaier LH, Mark DB. Relationship between physician and hospital coronary angioplasty volume and outcome in elderly patients. Circulation 1997; 95: 2485-91.
29. McGrath PD, Wennberg DE, Malenka DJ, Kellett MJ Jr, Ryan TJ Fr, O'Meara JR, Bradley WA, Hearne MJ, Hettleman B, Robb JF, Shubrooks S, VerLee P, Watkins MW, Lucas FL, O'Connor GT. Operator volume and outcomes in 12,998 percutaneous coronary interventions. Northern New England Cardiovascular Disease Study Group. $J$ Am Coll Cardiol 1998; 31: 570-6.

30. Hannan EL, Racz M, Ryan TJ, McCallister BD, Johnson LW, Arani DT, Guerci AD, Sosa J, Topol EJ. Coronary angioplasty volume-outcome relationships for hospitals and cardiologists. Jama 1997; 277: 892-8.

31. Ellis SG, Weintraub W, Holmes D, Shaw R, Block PC. King SB 3rd, Relation of operator volume and experience to procedural outcome of percutaneous coronary revascularization at hospitals with high interventional volumes. Circulation 1997; 95: 2479-84.

32. Kastrati A, Neumann FJ, Schomig A. Operator volume and outcome of patients undergoing coronary stent placement. J Am Coll Cardiol 1998; 32: 970-6.

33. McGrath PD, Wennberg DE, Dickens JD Jr, Siewers AE, Lucas FL, Malenka DJ, Kellett MA Jr, Ryan TJ Jr. Relation between operator and hospital volume and outcomes following percutaneous coronary interventions in the era of the coronary stent. Jama 2000; 284: 3139-44.

34. Moscucci M. Relationship between low operator volume and adverse outcom in comtemporary PCI practice: an analysis of a large quality controlled multicenter PCI database. (abstract). Circulation 2002; 106: suppl 1: 110876.

35. Legrand V, Vrolix M, De Bruyne B, Wijns W, Heyndrickx G, De Scheerder I, Taeymans Y, Vrints C, Materne P, Benit E, Col J, Boland de Keyser JM, Lafontaine P, Renkin J. BWGIC guidelines for training and quality control in adult interventional cardiology. Belgian Working Group of Invasive Cardiology. Acta Cardiologica 1997; 52: 507-14.

36. Meyer P, Barragan P, Blanchard D, Chevalier B, Commeau P, Danchin N, Fajadet J, Grand A, Lablanche JM, Machecourt J, Metzger JP, Monassier JP, Neimann JL, Puel J, Steg PG. Recommendations of the French Cardiac Society concerning the education of physicians performing coronarography and angioplasty, organization and equipment of coronarography and coronary angioplasty centers. Arch Mal Coeur Vaiss. 2000; 93: 147-158.

37. Magid DJ, Calonge BN, Rumsfeld JS, Canto JG, Frederick PD, Every NR, Barron HV. Relation between hospital primary angioplasty volume and mortality for patients with acute MI treated with primary angioplasty vs thrombolytic therapy. Jama 2000; 284: 3131-8.

38. Canto JG, Every NR, Magid DJ, Rogers WJ, Malmgren JA, Frederick PD, French WJ, Tiefenbrunn AJ, Misra VK, Kiefe CI, Barron HV. The volume of primary angioplasty procedures and survival after acute myocardial infarction. National Registry of Myocardial Infarction 2 Investigators. $N$ Engl J Med 2000; 342: 1573-80.

39. Vakili BA, R Kaplan, Brown DL. Volume-Outcome Relation for Physicians and Hospitals Performing Angioplasty for Acute Myocardial Infarction in New York State. Circulation 2001; 104: 2171-2176. 